\title{
Exame Papanicolaou: sentimentos relatados por profissionais de enfermagem ao se submeterem a esse exame
}

\author{
Pap smear screening: sensations reported \\ by nursing professionals when submitted to this test
}

Roberta Jeane Bezerra Jorge ${ }^{1}$

Maria Albertina Rocha Diógenes ${ }^{1}$

Francisco Antonio da Cruz Mendonça ${ }^{1}$

Luís Rafael Leite Sampaio ${ }^{1}$

Roberto Jorge Júnior ${ }^{1}$

'Grupo Saúde da Mulher,

Abstract This work sought to record the impressions of nursing assistants and technicians after submitting to Pap smear screening. This is a descriptive study using a qualitative approach conducted in September and October of 2006 with 35 employees of a public institution, which is a benchmark in gynecology in Fortaleza in the State of Ceará (Brazil). The data was collected through semi-structured interviews containing a recorded leading question and analyzed according to the methodological-theoretical reference of social phenomenology. The testimonials were separated in three groups: an exam that causes discomfort, fear and shame; an exam that causes anxiety about the results; and an exam that "makes me calm and relaxed". Despite the interviewees being part of an institution that cares for the prevention of cervical-uterine cancer in women, negative feelings about the Pap smear test were nonetheless report$e d$. The conclusion reached is that it is important to stage educational campaigns emphasizing the importance of empowerment of patients in order to minimize these aspects.

Key words Impressions, Pap smear screening, Women's Health, Uterine cervical neoplasm
Resumo Objetivou-se conhecer os sentimentos de auxiliares e técnicas de enfermagem ao se submeterem ao exame Papanicolaou. Trata-se de um estudo descritivo com abordagem qualitativa realizado nos meses de setembro a outubro de 2006, com 35 servidoras de uma instituição governamental referência em ginecologia na cidade de Fortaleza (CE). Os dados foram coletados através de entrevista semiestruturada, contendo uma questão norteadora gravada e analisada de acordo com referencial teórico metodológico da fenomenologia social. Os relatos foram agrupados em três temáticas: um exame que causa incômodo, medo e vergonha; um exame que gera ansiedade quanto aos resultados; e um exame que "me deixa calma e tranquila". Apesar de as entrevistadas pertencerem a uma instituição que cuida de mulheres na prevenção do câncer cérvico-uterino, elas não deixaram de emitir sentimentos negativos relacionados ao exame. Concluiu-se a importância de realizar projetos educativos, enfatizando a importância do empoderamento das usuárias a fim de minimizar essas questões.

Palavras-chave Sentimentos, Papanicolaou, Saúde da Mulher, Neoplasias do colo do útero 


\section{Introdução}

A colpocitologia oncótica ou Papanicolaou é um método manual realizado por profissionais enfermeiros e médicos que permite a identificação de células sugestivas de pré-invasão até lesões malignas, através de coloração multicrômica de lâminas contendo células cervicais esfoliadas.

O exame é realizado oportunamente nas consultas de planejamento familiar, pré-natal, ginecológica e outras. Geralmente, é realizado nas mesmas mulheres que frequentam os serviços de saúde, o que não diminui, significativamente, a incidência do câncer do colo uterino, apesar de este tipo de câncer ser uma das poucas afecções malignas, com história natural conhecida, que dispõe de uma política internacional para detecção precoce e erradicação ${ }^{1}$.

Com o intuito de otimizar os recursos disponíveis, o exame Papanicolaou deve ser oferecido às mulheres entre 25 e 65 anos e às que iniciaram a atividade sexual antes dessa faixa etária, com ênfase entre 45 e 49 anos (período que corresponde ao pico de incidência das lesões precursoras e antecede o pico de mortalidade pelo câncer). Após duas colheitas anuais negativas, a periodicidade poderá ser trienal, permitindo identificar os casos nos quais possa ter ocorrido um resultado falsonegativo. No entanto, o câncer cervical está entre os cânceres mais incidentes no sexo feminino, ocupando, respectivamente, o segundo e o terceiro lugares no mundo e no Brasil'2.

No mundo, a doença representa a segunda causa de morte na população feminina, sendo estimadas 240.000 mortes anualmente. Aproximadamente 500 mil casos novos ocorrem anualmente no mundo, e cerca de $80 \%$ desses casos em países em desenvolvimento. É considerada a quarta causa de óbito por câncer nas mulheres no Brasil, ocupando no Nordeste a segunda posição dos estados mais incidentes. Neste país, o câncer cervical representa $10 \%$ de todos os tumores malignos, e para o ano de 2008 as estimativas da incidência apontaram a ocorrência de 18.680 novos casos. Os índices de mortalidade não têm demonstrado queda nos últimos vinte anos, mesmo o país tendo sido um dos primeiros do mundo a realizar o exame preventivo ${ }^{3}$.

De acordo com o Ministério da Saúde, os fatores responsáveis pelos altos níveis de câncer cérvico-uterino e a não adesão ao exame Papanicolaou no Brasil devem-se à insuficiência de recursos humanos e de materiais disponíveis na rede de saúde para prevenção, diagnóstico e tratamento; utilização inadequada dos recursos exis- tentes; má articulação entre os serviços de saúde na prestação da assistência nos diversos níveis de atenção; indefinição de normas e condutas; baixo nível de informações de saúde da população em geral e insuficiência de informações necessárias ao planejamento das ações de saúde ${ }^{4}$.

Entre os fatores supracitados, além da insuficiência de recursos humanos, a demora das mulheres ou sua ausência ao serviço para realizar ou tomar conhecimento do resultado do exame preventivo pode estar associada ao modo como o profissional acolhe a usuária e como esta percebe o exame preventivo.

A percepção de mundo de cada pessoa é influenciada por seus valores, sua cultura, sua raça, suas experiências vividas, suas crenças, suas expectativas de vida e idéias preconcebidas e construídas ao longo de sua vida. Este modo de ser, viver, sentir e perceber o mundo traduz-se nos comportamentos observáveis de um indivíduo ou de uma coletividade ante as diversas situações cotidianas, entre elas as que envolvem o processo saúde-doença $\mathrm{a}^{5}$ - o que leva à reflexão de que a busca pelo exame Papanicolaou pode depender do seu significado para as usuárias e a partir de como o profissional conduz a relação de cuidador e orientador para com elas.

Cada mulher é um ser único e possui sua própria singularidade e compreensão sobre o contexto que envolve o exame citopatológico. Um procedimento, a princípio simples aos olhos do profissional, pode ser percebido pela mulher como uma experiência agressiva, tanto física quanto psicologicamente, pois a mulher que busca o serviço traz consigo suas bagagens social, cultural, familiar e religiosa ${ }^{6}$.

Sobre este assunto, evidencia-se um estudo realizado com funcionárias de indústrias têxteis em São Paulo, o qual identificou, entre as entrevistadas, que o exame Papanicolaou causava sensação de desconforto, vergonha e constrangimento, sentimentos estes que poderiam ter sido minimizados pelos profissionais de saúde durante a consulta ginecológica ${ }^{7}$. Esses sentimentos podem ser externados e vivenciados pela mulher de forma singular, conforme a visão de mundo de cada uma, podendo ser apreendidos como uma sensação de impotência, desproteção e perda do domínio sobre o corpo que a própria posição ginecológica proporciona ${ }^{8}$.

Uma das autoras da presente pesquisa atua há alguns anos como enfermeira de uma instituição estadual, referência em ginecologia para o Estado do Ceará, na qual grande parte dos servidores é do sexo feminino, e é constantemente re- 
quisitada por profissionais de nível médio de enfermagem para esclarecer questões na área ginecológica: queixas ginecológicas, laudos citológicos, orientações medicamentosas. Essa situação sensibilizou a autora a se preocupar com a condição dessas servidoras em relação ao exame Papanicolaou. Ela observou que as usuárias do serviço, ao realizarem esse exame, evidenciam sentimentos de vergonha, ansiedade, medo do exame e do resultado, absenteísmo para o resultado, bem como do seguimento do tratamento. Então, com o intuito de compreender se essas servidoras também apresentam sentimentos similares, pois são mulheres e estão inseridas num contexto sociocultural, questiona-se: quais os sentimentos de auxiliares e técnicas de enfermagem ao se submeterem ao exame Papanicolaou?

Diante dessa problemática, objetivou-se conhecer os sentimentos de auxiliares e técnicas de enfermagem ao se submeterem ao exame Papanicolaou.

\section{Métodos}

Trata-se de um estudo do tipo descritivo com abordagem qualitativa, na qual se coletam e analisam materiais pouco estruturados e narrativos que propiciam campo livre ao rico potencial das percepções e subjetividades dos seres humanos ${ }^{9,10}$. As inquisições qualitativas, em razão da sua ênfase nas realidades dos sujeitos, exigem um mínimo de estrutura e um máximo de envolvimento do pesquisador, uma vez que elas buscam abranger os sujeitos cuja experiência está sendo estudada.

O estudo foi realizado em Fortaleza (CE), no período de setembro a outubro de 2006, no Instituto de Prevenção do Câncer do Ceará (IPCC), referência estadual de atenção à saúde com atendimento ambulatorial e hospitalar especializado na prevenção e no tratamento do câncer ginecológico e de mama, além de exames complementares e tratamento terapêutico especializado.

Devido à relevância desta pesquisa e à diversidade de atuação dos profissionais de nível médio de enfermagem, optou-se, inicialmente, pela realização deste estudo na única instituição de nível secundário do Estado do Ceará. Porém, ressalta-se que a pesquisa será ampliada através de um projeto de extensão da Universidade de Fortaleza, que se realizará em unidades de saúde nos níveis da atenção básica e terciária com as servidoras de nível médio de enfermagem que trabalham na área de saúde da mulher na rede de serviços do município de Fortaleza (CE).
A amostra do estudo constituiu-se de 35 mulheres que aceitaram participar da pesquisa, todas servidoras que trabalham no cargo de auxiliares ou técnicas de enfermagem na referida instituição, nas quais 27 são auxiliares e oito são técnicas de enfermagem.

Foi utilizada uma entrevista semiestruturada contendo perguntas fechadas e uma aberta (questão norteadora). Foi garantido anonimato, bem como solicitada permissão para gravar as falas relacionadas à questão aberta e para que assinassem o termo de consentimento. As perguntas fechadas contemplaram os aspectos sociodemográficos que foram abordados em função de frequência absoluta e índices percentuais. Já para a questão norteadora, optou-se por analisá-la segundo a abordagem qualitativa da fenomenologia social, pois o propósito foi compreender os sentimentos das mulheres através de descrições das experiências vivenciadas ao realizar o exame preventivo sem, contudo, sofrer influências dos pesquisadores ${ }^{11}$. O referencial teórico baseado na fenomenologia social de Alfred Schutz explica que as pessoas agem em função de motivações dirigidas a objetivos, sendo que as razões para suas ações estão marcadas pelas experiências vividas ${ }^{12}$.

Os critérios de seleção da amostra foram tão somente o fato de as mulheres trabalharem na instituição e desejarem participar da pesquisa mediante assinatura no termo de consentimento livre e esclarecido, independentemente de faixa etária, escolaridade, nível socioeconômico e estado civil.

Para a análise da pesquisa, procedeu-se à transcrição dos depoimentos na íntegra. Com a finalidade de elaborar as categorias em temas, utilizaram-se os seguintes passos: leitura aprofundada das entrevistas, com o intuito de apreender o sentido e o significado dos discursos, releitura dos discursos visando discriminar as unidades de significados, focalizando o fenômeno estudado; buscaram-se as convergências entre as unidades identificadas expressando seus significados; e, por último, fez-se a síntese de todas as unidades e integração dos insights contidos nelas e transformados em uma descrição consistente da estrutura retirada do fenômeno interrogado ${ }^{11}$.

A partir dos relatos das entrevistadas, emergiram três temáticas: $26(74,28 \%)$ das participantes informaram um exame que causa incômodo, medo e vergonha, enquanto cinco $(14,29 \%)$ relataram um exame que gera ansiedade quanto ao resultado, e apenas quatro $(11,43 \%)$, um exame que "me deixa calma e tran- 
quila”. As temáticas foram organizadas em ordem decrescente do percentual. Para preservar o anonimato das entrevistadas, elas foram denominadas por nomes de pedras preciosas.

Quanto aos aspectos éticos e legais da pesquisa, esta foi realizada mediante autorização do Comitê de Ética em Pesquisa da Universidade de Fortaleza, no intuito de atender às exigências do Conselho Nacional de Saúde, o qual se refere às diretrizes e normas regulamentadoras de estudo envolvendo seres humanos ${ }^{13}$.

\section{Resultados e discussão}

\section{Caracterização das mulheres}

Em relação aos dados sociodemográficos, como se pode ver na Tabela 1, observou-se que a idade entre 25 e 59 anos foi predominante no estudo, correspondendo a um total de 32 $(91,43 \%)$ das mulheres entrevistadas. Essa faixa etária é a indicada para realização do exame preventivo pelo Programa Nacional de Controle do Câncer de Colo do Útero, órgão que objetiva aumentar a oferta deste exame principalmente para essa faixa etária, priorizando as que nunca o realizaram e as que são sexualmente ativas. Contudo, a adesão a esse exame, no Brasil, ainda é insuficiente, uma vez que existem cerca de seis

Tabela 1. Distribuição das servidoras quanto a faixa etária, renda familiar e escolaridade, Instituto de Prevenção do Câncer do Ceará - Fortaleza (CE), 2006.

\begin{tabular}{lrr}
\hline \multicolumn{1}{c}{ Variáveis sociodemográficas } & $\mathbf{n}$ & $\%$ \\
\hline Idade (anos) & & \\
$\quad<25$ & 3 & 8,57 \\
25 a 60 & 32 & 91,43 \\
$\quad$ Total & 35 & 100 \\
Escolaridade (anos estudados) & & \\
$\quad$ Até 8 & 2 & 5,71 \\
Até 12 & 7 & 20,00 \\
Até 15 & 18 & 51,43 \\
15 & 8 & 22,86 \\
Total & 35 & 100 \\
Renda familiar (salários mínimos) & & \\
1 a 2 & 19 & 54,29 \\
2 a 3 & 9 & 25,71 \\
3 a 4 & 5 & 14,29 \\
$>4$ & 2 & 5,71 \\
Total & 35 & 100 \\
\hline
\end{tabular}

milhões de mulheres na faixa etária indicada que nunca realizaram o exame preventivo, e cerca de $40 \%$ das que o fazem não retornam para buscar o resultado. Essa afirmativa é preocupante, pois a cada ano vão a óbito milhares de mulheres que, se tivessem realizado o procedimento periodicamente, poderiam ter se prevenido ou tratado a tempo a doença, evitando a sua progressão para malignidade e consequente causa de morte ${ }^{2}$.

Quanto ao nível de escolaridade, 18 (51,43\%) apresentaram 15 anos de estudo, sendo que a média de escolaridade da população brasileira em idade ativa, para o ano de 2005, foi de 6,64 anos de estudo ${ }^{14}$. Pode-se perceber que as entrevistadas estão com nível de escolaridade acima da média nacional, o que possibilita a acessibilidade e a compreensão das informações acerca das práticas em lidar com as questões de saúde. O nível de escolaridade é um importante item a ser considerado na adesão a medidas preventivas para o câncer de colo uterino. Portanto, o analfabetismo e o baixo nível educacional são fatores que podem impedir ou dificultar a informação sobre essa doença, sobre a utilização dos serviços de saúde, sobre os fatores de risco, sobre a importância do exame preventivo e do esclarecimento de possíveis dúvidas ${ }^{15}$.

Quanto à renda familiar, o grupo estudado recebe, em média, dois salários mínimos, representando 19 (54,29\%) das entrevistadas. Este dado evidencia que a renda dessas mulheres encontrase abaixo da média brasileira per capita, uma vez que as principais características da distribuição do rendimento das pessoas economicamente ativas no Brasil, em 2006, eram correspondentes a 2,32 salários mínimos. Os trabalhadores brasileiros tiveram aumento de $7,2 \%$ em seus rendimentos de 2005 para 2006, passando a ganhar, em média, $\mathrm{R} \$ 883,00$ por mês. Tal resultado foi revelado na Pesquisa Nacional por Amostra de Domicílios (PNAD) 2006, divulgada pelo Instituto Brasileiro de Geografia e Estatística (IBGE), sendo o maior crescimento, nessa comparação, desde 1995. Um dos fatores determinantes para esse crescimento foi o ganho real do salário mínimo, de $13,3 \%$ em 2006, em relação a $2005^{16}$.

A literatura tem relatado que, à medida que diminui o nível socioeconômico, aumenta significativamente a prevalência de mulheres sem cobertura pelo exame Papanicolaou ${ }^{17,18}$. O baixo nível socioeconômico pode dificultar o acesso aos serviços de saúde, devido a barreiras geográficas, tais como distância ao serviço de saúde em relação às usuárias, dificuldade de transporte, burocracia e tempo gasto na marcação de consulta. 
Existe uma associação muito íntima entre baixo nível de escolaridade e renda familiar, fazendo com que mulheres enquadradas nessa relação sejam mais suscetíveis ao acometimento do câncer cervical. Possivelmente, o nível socioeconômico e cultural seja uma influência de forma direta na detecção dessa doença ${ }^{15}$. Nessa mesma linha de raciocínio, um estudo de revisão sistemática da literatura sobre a cobertura do exame Papanicolaou no Brasil identificou desigualdades regionais na sua cobertura, visto que a maioria das mulheres que realizava o exame concentrava-se nas grandes cidades das regiões Sul e Sudeste do país e as submetidas ao exame eram, geralmente, as mesmas. E as que não o realizavam, apresentavam escolaridade e renda familiar baixas e pertenciam à faixa etária mais jovem ${ }^{19}$. Em outra pesquisa, feita na cidade brasileira de São Paulo e nas cidades japonesas de Kobe e Kawasaki, sobre a vivência de mulheres japonesas e brasileiras descendentes de japoneses, quanto ao exame preventivo do câncer cérvico-uterino, identificou-se que as entrevistadas conheciam a finalidade desse exame, influenciando sua adesão, o que dependia, principalmente, de bons níveis de escolaridade e socioeconômico ${ }^{20}$. A seguir, será apresentada a descrição das temáticas.

\section{Sentimentos das mulheres ao realizarem o exame para prevenção de câncer de colo do útero}

No ato do exame ginecológico, cada mulher tem sua própria percepção sobre os procedimentos que envolvem a prevenção do câncer cérvicouterino. Algumas mulheres podem reconhecê-lo como um procedimento simples, mas outras podem não ter essa mesma opinião, tendo em vista que cada pessoa traz consigo suas raízes culturais, aflorando diferentes sentimentos. Em nossa sociedade, a educação da mulher sempre foi permeada de palavras cheias de proibições e inibições, compondo um quadro de total anulação dos órgãos genitais ${ }^{21}$.

Serão disponibilizados, a seguir, os sentimentos relatados pelas entrevistadas ao realizarem o exame Papanicolaou.

\section{Um exame que causa incômodo, vergonha e medo}

Os sentimentos relatados pelas mulheres ao se submeteram ao exame preventivo, como se pode observar nas verbalizações a seguir, geram incômodo, medo e vergonha pela maioria.

Como o exame ginecológico constitui-se, em última instância, na exposição do que a mulher tem de mais íntimo, a sua genitália, tão cercada de tabus e proibições, evidencia a percepção de que sentimentos negativos relacionados ao exame podem ser oriundos das experiências restritivas vivenciadas ao longo da vida da mulher sobre sua sexualidade, bem como da falta de informações sobre anatomia e fisiologia do corpo, o papel da mulher na sociedade, relações de gênero, dentre outras.

No discurso a seguir, está expresso o sentimento de vergonha quando se colocam na posição ginecológica, expondo a genitália: É uma sensação muito constrangedora e desagradável para a mulher [...] não gosto de ficar com as pernas abertas (Esmeralda). Rubi reforça o incômodo e a vergonha que o exame causa: Além de incomodar, é vergonhoso ficar exposta naquela posição.

O modo como algumas mulheres se manifestam ao terem que expor seu corpo e tê-lo manipulado e examinado por um profissional revela o quanto a sexualidade tem influência sobre a vida da mulher ${ }^{22,23}$

Em um estudo de caso realizado com 24 mulheres, entre 18 e 60 anos, que buscaram o serviço de prevenção de câncer cérvico-uterino em uma Unidade Básica de Saúde de Fortaleza, além da vergonha de mostrar o corpo, algumas mulheres manifestaram desconforto durante a posição ginecológica, referindo-se ao fato de não ficarem despidas nem mesmo para seu cônju$\mathrm{ge}^{22}$. Portanto, são vários os motivos que interferem na credibilidade e no grau de adesão das mulheres aos serviços e programas de prevenção em saúde.

Segundo Galvão e Díaz ${ }^{15}$, algumas mulheres referem que o exame se caracteriza como um procedimento que leva à invasão da privacidade e da integridade corporal; outras acham, ainda, que o exame as expõe a uma experiência dolorosa, embaraçosa e desagradável.

Em outra pesquisa realizada em uma Unidade Básica de Saúde, na cidade de Natal (RN), com 120 mulheres, a respeito do conhecimento sobre o exame preventivo, identificou-se que sentimentos como medo e vergonha foram as principais causas atribuídas por 35 (42\%) mulheres para a não realização do exame de Papanicolaou ${ }^{8}$. Outro estudo, realizado no município de São Paulo (SP), revelou que os principais motivos referidos pelas mulheres para a realização do teste estão na demanda espontânea, na recomendação médica e na presença de queixas ginecológicas. Dentre os fatores que se destacam para não realização do exame estão: ausência de problemas ginecológicos, vergonha ou medo e dificuldades de acesso aos serviços ${ }^{19}$. 
O profissional, ao realizar o exame preventivo sem a devida explicação do procedimento, da sua importância, e ainda de forma fria e descuidada, pode potencializar tais sentimentos negativos, além de promover desconforto físico e psicológico $^{24}$. Esta realidade pode ser determinada e agravada pela ausência de espaços suficientes de reflexão para as mulheres incorporarem e analisarem temas que integrem o seu mundo emocional e afetivo, assim como os processos de autoconhecimento e empoderamento. Esses espaços poderiam ser uma ferramenta de prevenção de situações e de agravos.

Em pesquisa feita com nove mulheres cadastradas no programa de prevenção do câncer de colo de útero de uma Unidade Básica de Saúde do Norte do Paraná, revelou-se que o exame ginecológico foi o mais citado pelas mulheres como temido e vergonhoso - fato relacionado aos fatores culturais de desvalorização da feminilidade; educação/informação sexual inadequada ou inexistente; e, ainda, a desconhecimento, medo e vergonha em relação aos genitais e ao exame ginecológico ${ }^{25}$. Em vista disso, pode-se compreender que o sentimento de vergonha atribuído em relação à exposição dos genitais e zonas erógenas seja produzido pelo fato da constante associação entre exposição da genitália e sexualidade.

Esse aspecto é compartilhado em outros estudos ${ }^{26}$, nos quais os autores relataram que os sentimentos constrangedores, citados pelas mulheres no momento do exame ginecológico, se relacionam ao medo da descoberta de uma patologia grave, ou sem cura, e à inibição proveniente da exposição das partes do corpo correlacionadas com a feminilidade e a intimidade da mulher.

Questões como essas devem ser mais bem trabalhadas pelos profissionais de saúde, no sentido de preparar psicologicamente a mulher, durante o acolhimento, devendo ser discutidas de acordo com cada cultura, respeitando a sexualidade feminina, evitando, assim, bloqueio na esfera da subjetividade.

Apesar de as entrevistadas deste estudo evidenciarem sentimentos de vergonha e incômodo, o exame de prevenção também é reconhecido como uma forma de se cuidar. Demonstraram, ainda, preocupação e interesse em conhecer suas condições de saúde e reconheceram a importância da promoção da saúde e da prevenção da doença. Esse reconhecimento é apreendido no relato de Safira: Acho desagradável e constrangedor, mas é necessário fazer, temos que nos proteger, até porque trabalhamos aqui, e temos incentivos e conhecimentos da sua importância.
Identificou-se que a preocupação demonstrada sobre o "cuidar de si", além de estar associada ao fato de as entrevistadas trabalharem em uma instituição de referência na prevenção e no tratamento do câncer ginecológico, pode estar relacionada ao significado que atribuem ao câncer e o que representa em suas vidas.

Em estudo de Duavy et al. ${ }^{22}$, verificou-se que os motivos que levam as mulheres a buscarem a assistência de um profissional de saúde especializado são a identificação de problemas em si e a possibilidade de serem vitimadas pelo câncer ginecológico, o qual é percebido como algo temível e ameaçador.

Sobre o medo, alguns relatos evidenciaram que tal sentimento está relacionado ao exame propriamente dito e à expectativa de as mulheres terem algum problema de saúde: Tenho medo do que vão encontrar (Citrino). Outra entrevistada evidenciou: Fico receosa quanto ao resultado, tenho medo de estar com a doença (Peridoto). Alexandrita também comentou: Sabe aquele friozinho na barriga? A gente fica com medo de alguma coisa, alguma doença.

O medo é um sentimento de inquietação diante de um perigo real ou imaginário, desencadeado a partir de uma situação concreta, presente e maléfica. E caso tome proporções maiores, age como sinal de condicionamento e antecipador de sofrimento ${ }^{27}$.

Esse sentimento representa um estado emocional presenciado em alguns indivíduos que se sentem ameaçados na continuidade da rotina de vida. Surge a cada situação nova, inesperada, que representa um perigo ${ }^{28}$. O medo de ter a doença deixou as entrevistadas preocupadas quanto ao laudo citológico, sentimento que pode interferir na busca do resultado.

O câncer ainda tem conotações negativas e é representado pelas suas consequências trágicas como a iminência presente do medo de morrer, carregado de estigmas de discriminação e rejeição social, desde o meio familiar até as perdas de atividades produtivas no nível físico, afetivo, familiar, econômico, social e cultural ${ }^{29}$.

\section{Um exame que gera ansiedade quanto ao resultado}

O câncer é a doença crônico-degenerativa que mais causa pavor, complicações, mudança de hábitos, dificuldades diversas, alterações emocionais e a busca de justificativas para a sua presença ${ }^{17}$. Nesse sentido, as mulheres deste estudo, ao se submeterem ao exame preventivo, sentiram-se ansiosas quanto ao resultado, o que pode ser cons- 
tatado na fala das entrevistadas: Eu fico tensa $e$ preocupada com o resultado do exame (Ametista). Berilo e Topázio mencionaram: Na hora do exame fico nervosa [...] tenho medo do resultado e não sossego enquanto não sei do resultado [...] Bate uma ansiedade. Zircônio complementou: Fico ansiosa de fazer o exame e aflita à espera do resultado.

A ansiedade é experimentada por cada uma de maneira particular e de acordo com sua experiência de vida ${ }^{28}$. Observa-se que esse sentimento deixa as mulheres em situação desconfortável, podendo gerar alterações somáticas em que se preveem situações desagradáveis, reais ou não. Portanto, deve-se aproveitar a oportunidade para conquistar a confiança da clientela, passo importante na conscientização sobre a relevância do exame preventivo, pois uma atitude negativa do profissional, no momento do exame, poderá gerar tensão devido ao medo e à ansiedade de sua realização e repercutir em resultados falso-negativos, ocasionando o afastamento de outras mulheres do serviço de prevenção do câncer ginecológico.

Considera-se que os profissionais qualificados para a realização desse exame devem manter a equipe preparada para receber essas mulheres, desde o acolhimento até a busca do resultado do exame, criar vínculos com a usuária, para que ela se sinta compreendida, cuidada, encorajada e segura para realizar o exame.

\section{Um exame}

que "me deixa calma e tranquila"

No momento em que o profissional de saúde acolher a usuária, deve se identificar, explicar os procedimentos, esclarecer seus questionamentos, deixando-a tranquila. Acredita-se que as emoções negativas tenderão a dar lugar à sensação de alívio e de bem-estar, embora, nem sempre, o diagnóstico imediato seja completamente seguro. Pesquisadores de um ambulatório em Minas Gerais evidenciaram nos discursos das mulheres a importância que atribuem ao cuidar-se. Elas disseram que realizaram o exame colpocitológico para evitar o câncer cérvico-uterino e que tinham ciência de que este exame é um meio eficaz na prevenção e combate à enfermidade, reconhecendo seus benefícios ${ }^{30}$.

São poucas as mulheres que, diante de um exame ginecológico, demonstram tranquilidade, mas tal sentimento foi relatado por algumas entrevistadas. Sobre esse assunto, as pesquisadas afirmaram: Sinto-me bem por saber que estou me cuidando, por isso fico tranquila, pois é para prevenir o câncer de útero (Sodalita). Turquesa complementou: Para mim é natural, faz parte do cui- dar de nossa saúde, fico à vontade e calma, até porque as doutoras tranquilizam a gente.

Pelos discursos, percebe-se que a informação sobre o exame preventivo representa relevante critério a considerar na adesão ao exame. Grande parte dos sentimentos, anteriormente relatados nesta pesquisa, pode ser originária de experiências negativas sofridas pelas mulheres durante o procedimento, quando realizado sem explicação do seu significado, impossibilitando a criação de um espaço de autoconhecimento do corpo e da sexualidade da mulher.

Oliveira e Pinto ${ }^{23}$, ao estudarem 14 mulheres atendidas em unidades de saúde da família na cidade de São Paulo, concluíram que o diálogo é um instrumento fundamental do profissional de saúde, deixando as mulheres relaxadas e tranquilas com a realização do Papanicolaou. Portanto, a conversa e a escuta devem acontecer em todos os momentos do encontro com a usuária, tanto dentro do serviço de saúde quanto na comunidade.

De acordo com o Programa Nacional de Humanização da Assistência Hospitalar (PNHAH), a relação profissional-cliente envolvida em um clima de empatia e confiança tornase fundamental para garantir a adesão aos programas de prevenção de doenças de forma tranquila, uma vez que as relações de acolhimento e de vínculo promovem o respeito à dignidade humana ${ }^{31}$.

A confiança é considerada a base de qualquer relacionamento afetivo, que permeia a vida de um indivíduo em diversos momentos e relações, com consequências que afetam, de maneira importante, tanto a sua trajetória quanto a daqueles com os quais interagem. As emoções e os sentimentos existentes entre as pessoas se constituem em parte importante das relações entre elas e, consequentemente, influem diretamente na construção da confiança, visto que investimentos emocionais são feitos por ambas as partes.

Pelos depoimentos e observações das entrevistadas, constata-se que, além da relação de confiança depositada nos profissionais que realizavam sua consulta ginecológica, a informação sobre o exame preventivo representou relevante critério a considerar na adesão ao exame. Acrescenta-se que o profissional de saúde, ao valorizar a dimensão humana e subjetiva, presente em todo ato de assistência à saúde, propicia melhores condições de trabalho para os profissionais e a conquista de melhor qualidade de atendimento à saúde da usuária, além de estimular a criação de vínculos e consequente adoção de medidas preventivas e de tratamento. 


\section{Considerações finais}

O referencial fenomenológico busca o significado da experiência vivida, compreendendo o homem, sujeito do cuidado. Assim, este estudo procurou compreender a mulher inserida numa dada sociedade, histórica e culturalmente situada.

Constatou-se com as entrevistadas que, ao realizarem o exame, apresentaram sentimentos causadores de incômodo, medo e vergonha; outras relataram ansiedade quanto ao resultado; e outras informaram que ficavam "calmas e tranqüilas" durante a realização do exame ginecológico.

Desse modo, deve-se compreender a forma como uma determinada população percebe, sente e vive a saúde, pois é o primeiro passo para definir estratégias de intervenções mais eficientes e adequadas às reais necessidades da comunidade. Assim, a compreensão dos significados emergidos dos discursos das mulheres submetidas ao exame colpocitológico possibilitará o direcionamento de um novo caminho no assistir/cuidar dessa clien- tela pela equipe de saúde, o que contribui para a transformação de uma prática assistencial e melhor percepção das usuárias, proporcionando, em última instância, um atendimento mais adequado às necessidades da população feminina, um cuidar humanizado que, certamente, ocasionará maior adesão ao exame de Papanicolaou.

Portanto, é necessária uma atuação diferenciada dos profissionais da saúde com as mulheres em relação ao exame de prevenção. Uma atuação com envolvimento, com respeito à sua intimidade, à sua privacidade, ao seu direito de conhecer e de poder dialogar sobre seu processo saúde-doença.

Finalmente, salienta-se que o bom relacionamento interpessoal entre usuárias e profissional de saúde é de suma importância, ao considerar essa relação empática e de confiança, o que poderá contribuir para a tranquilidade durante a realização do exame e o estabelecimento de vínculos, promovendo, dessa forma, a saúde das coletividades humanas.

\section{Colaboradores}

RJB Jorge, MAR Diógenes, FAC Mendonça, LRL Sampaio e R Jorge Júnior são igualmente responsáveis pela definição do objeto de estudo, da abordagem metodológica, pesquisa bibliográfica, elaboração e aplicação do instrumento, análise dos dados, redação, revisão do artigo e aprovação para publicação. 


\section{Referências}

1. Brenna SMF, Rodrigues TMC, La Corte AC. Diagnóstico e tratamento do câncer do colo do útero. Diagnóstico \& Tratamento 2002; 8(1):35-40.

2. Brasil. Ministério da Saúde. Instituto Nacional de Câncer. Programa Nacional de Controle do Câncer do Colo do Útero e de Mama. 2002 [acessado 2006 jun 10]: [cerca de 38p.]. Disponível em: http:// www.inca.gov.br/conteúdo-view.asp?id=140

3. Brasil. Ministério da Saúde. Instituto Nacional de Câncer. Estimativa 2008: incidência de câncer. 2008 [acessado 2008 jan 10]: [cerca de 15p.]. Disponível em: http://www.inca.gov.br/estimativa/2008/index. asp?link=tabelaestados.asp\&UF=BR

4. Brasil. Ministério da Saúde. Controle dos cânceres de colo de útero e de mama: Cadernos de Atenção Básica. Brasília: Secretaria de Atenção à Saúde, Departamento de Atenção Básica de Saúde, Ministério da Saúde; 2006. (Série A. Normas e Manuais Técnicos).

5. Pelloso SM, Carvalho MDB, Higarashi IH. Conhecimento das mulheres sobre o câncer cérvico-uterino. Acta Scientiarum Health Sciences 2004; 26(2):319-324.

6. Lopes RML. A mulher vivenciando o exame ginecológico na presença do câncer cérvico-uterino. Rev Enferm UERJ 1998; 2(2):165-170.

7. Ferreira MLM, Oliveira C. Conhecimento e significado para funcionárias de indústrias têxteis sobre prevenção do câncer do colo-uterino e detecção precoce do câncer da mama. Rev Bras Cancerol 2006; 52(1):5-15.

8. Davim RMB, Torres GV, Silva RAR, Silva DAR. Conhecimento de mulheres de uma Unidade Básica de Saúde da cidade de Natal/RN sobre o exame de Papanicolau. Rev Esc Enferm USP 2005; 39(3):296302.

9. Minayo MC. O desafio do conhecimento: pesquisa qualitativa em saúde. 4a ed. São Paulo: Hucitec; 1996.

10. Polit DF, Hungler BP. Fundamentos de pesquisa em Enfermagem. 3a ed. Porto Alegre: Artes Médicas; 1995.

11. Merighi MAB. Fenomenologia. In: Merighi MAB, Praça NS, organizadores. Abordagens teórico-metodológicas qualitativas: a vivência da mulher no período reprodutivo. Rio de Janeiro: Guanabara Koogan; 2003. p. 31-38.

12. Capalbo RYS. Metodologia das ciências sociais: a fenomenologia de Alfred Schutz. 2a ed. Londrina: Universidade Estadual de Londrina; 1998.

13. Brasil. Ministério da Saúde. Conselho Nacional de Saúde. Comissão de Ética em Pesquisa. Resolução $n^{\circ}$ 196: sobre pesquisa envolvendo seres humanos. Brasília: Conselho Nacional de Saúde; 1996.

14. Brasil. Ministério da Ciência e Tecnologia. Média dos anos de estudo da população em idade ativa. [documento na Internet]. 2005 [acessado 2007 ago 3]. Disponível em: http://acessibilidade.mct.gov.br/ index.php/content/view/8480.html

15. Galvão L, Díaz J. Saúde sexual e reprodutiva no Brasil: dilemas e desafios. São Paulo: Hucitec; 1999.

16. Segundo U. Portal do mundo do trabalho. [site na Internet]. 2007 [acessado 2007 set 15]. Disponível em: http://www.cut.org.br/site/start.cut?infoid= $13316 \& \operatorname{sid}=6$
17. Waitzberg DL. Dieta, nutrição e câncer. São Paulo: Atheneu; 2006.

18. Pinho AA, França Júnior I, Shraiber LB, D’Oliveira AFLP. Cobertura e motivos para a realização ou não do teste de Papanicolaou no município de São Paulo. Cad Saude Publica 2003; 19(2):303-313.

19. Martins LFL, Thuler LCS, Valente JG. Cobertura do exame de Papanicolaou no Brasil e seus fatores determinantes: uma revisão sistemática da literatura. Rev Bras Ginecol Obstet 2005; 27(8):485-492.

20. Chubaci RYS, Merichi MAB. Exame para detecção precoce do câncer cérvico-uterino: vivência das mulheres da cidade de Kobe e Kawasaki, Japão e São Paulo, Brasil. Rev Bras Saúde Matern Infant 2005; 5(4):471-481.

21. Salas VLB. A feminilidade: uma revisão da fase fálica. Porto Alegre: Artes Médicas; 1990.

22. Duavy LM, Batista FLR, Jorge MSB, Santos JBF. A percepção da mulher sobre o exame preventivo do câncer cérvico-uterino: estudo de caso. Cien Saude Colet 2007; 12(3):733-742.

23. Oliveira MM, Pinto IC. Percepção das usuárias sobre as ações de prevenção do câncer do colo do útero na Estratégia Saúde da Família em uma Distrital de Saúde do município de Ribeirão Preto, São Paulo, Brasil. Rev Bras Saúde Matern Infant 2007; 7(1):31-38.

24. Pinho AA, França-Júnior I. Prevenção do câncer de colo do útero: um modelo teórico para analisar o acesso e a utilização do teste de Papanicolaou. Rev Bras Saúde Matern Infant 2003; 3(1):95-112.

25. Cestari MEW. A influência da cultura no comportamento e prevenção do câncer [dissertação]. Ribeirão Preto, SP: Escola de Enfermagem de Ribeirão Preto, Universidade de São Paulo; 2005.

26. Rodrigues DP, Fernandes AFS, Silva RM. Percepção de algumas mulheres sobre o exame de Papanicolaou. Esc Anna Nery Rev Enferm 2001; 5(1):113118.

27. Myra \& Lopes E. Os quatro gigantes da alma: o medo, a ira, o dever, o amor. Rio de Janeiro: José Olímpio; 1996.

28. Gois CFL, Juaréz GMR, Sawada NO. Ansiedade e medo: avaliação crítica dos artigos na área da saúde. [site na Internet]. 2002 [acessado 2007 jul 14]. Disponível em http://www.proceedings.scielo.br/pdf/ sibracen/n8v2/v2a071.pdf

29. Linard AG, Silva FAD, Silva RM. Mulheres submetidas a tratamento para câncer de colo uterino: percepção de como enfrentar a realidade. Rev Bras Cancerol 2002; 48(4):493-498.

30. Paula AF, Madeira AMF. O exame colpocitológico sob a ótica da mulher que o vivencia. Rev Esc Enferm USP 2003; 37(3):88-96.

31. Teixeira RR. Humanização e atenção primária à saúde. Cien Saude Colet 2005; 10(3):585-597.

Artigo apresentado em 27/04/2008

Aprovado em 18/08/2008

Versão final apresentada em 29/10/2008 